\title{
LIMA BARRETO: UM PINGENTE ENTRE A LITERATURA E A REALIDADE
}

\author{
Camila Marcelina Pasqual ${ }^{56}$
}

RESUMO: $\mathrm{O}$ artigo, intitulado Lima Barreto: um pingente entre a literatura e a realidade, examina a forma como o escritor João Antônio retrata a vida do povo do subúrbio tentando resgatar a "voz" dos excluídos da periferia das grandes metrópoles e como tal tentativa de resgate determina a dinâmica de sua literatura. Ao mesmo tempo, avalia como a obra do romancista carioca Lima Barreto influenciou a produção literária do contista paulistano, levando-o a escolher retratar o mundo dos excluídos dos subúrbios: prostitutas, jogadores de sinuca e malandros, a partir da visão de mundo destes. Para tanto, o artigo utiliza as contribuições de autores como Antonio Candido, no que diz respeito à questão da literatura engajada, e Antonio Arnoni Prado para avaliar a influência de Lima Barreto sobre a produção contista de João Antônio. Prado também contribui para a análise da "herança" barretiana de João Antônio. O artigo recorre também às contribuições de Alfredo Bosi, sobre a afinidade de João Antônio e Lima Barreto para com as "classes excluídas".

Palavras-chave: João Antônio; Lima Barreto; Exclusão Social; Subúrbio; Processo de Urbanização.

ABSTRACT: The article, entitled Lima Barreto: um pingente entre a literatura e a realidade, examines the way how writer João Antônio portrays the life of suburban people to rescue the "voice" of great metropolis peripheral' excluded and how this attempt of rescue determines João Antônio's literature dynamic. Simultaneously, evaluates the way novelist Lima Barreto's literary production influenced literary production of this São Paulo's short story teller, making him decides to portrays the world of suburban excluded: prostitutes, pool players and hustlers. To achieve this, article uses the contributions of authors like Antonio Candido, about the question of engaged literature, and Antonio Arnoni Prado to evaluate the influence of Lima Barreto over João Antônio's short stories. Prado also

\footnotetext{
${ }^{56}$ Doutora em Literatura pela Universidade Federal de Santa Catarina-UFSC. Professora da Faculdade Educacional da Lapa (FAEL).
} 
contributes to the analyses of João Antônio's "barretian heritage" Article also recurs to the contributions of Alfredo Bosi, about João Antônio and Lima Barreto's affinity with excluded social classes.

Key-words: João Antônio; Lima Barreto; Social Exclusion; Suburb; Urbanization Process.

Antonio Candido define a Literatura Brasileira como interessada e voltada "para a construção duma cultura válida no país." (CANDIDO, 1975, p.18), sendo as literaturas brasileira e latino-americana marcadas por uma preocupação com a formação da identidade nacional, distinguindo-se da "velha" literatura europeia. O crítico aponta para a necessidade de uma "tomada de consciência" dos escritores no sentido de escrever uma proposta literária engajada, visando destacar a importância de se retratar a "realidade brasileira".

Esta mesma consciência da necessidade de retratar a realidade do país sempre foi uma das maiores preocupações do escritor João Antônio, para quem, a literatura precisa estar ligada à realidade do que ele denominava povo e mostrar não apenas o potencial e qualidades deste, como também suas fragilidades, problemas e deficiências, produzindo o que poderíamos chamar de verdadeira "radiografia" da vida da população brasileira. Isto é o que, para o autor, se pode chamar de autêntica literatura. (ASSIS, 1955, p. 135) ) $^{57}$

O artigo se propõe a examinar a obra contista de João Antônio com vistas a verificar a forma pela qual o escritor paulistano desenvolve tal "radiografia" da vida do povo brasileiro. Objetiva, também, aquilatar a importância da obra e vida de Lima Barreto sobre a obra de João Antônio, verificando os pontos de contato entre as produções literárias dos dois escritores.

Ressalte-se que, para João Antônio, uma verdadeira literatura brasileira necessita comprometer-se, engajar-se na busca da realidade brasileira, dos elementos que realmente fazem parte da vida da população. Tal realidade, explica o escritor, deve ser apresentada a partir de uma visão de dentro para fora, com o escritor "dando voz" às classes desfavorecidas da sociedade, ao invés de lhes emprestar uma voz “artificial”, plena da visão e preconceitos daquele que escreve.

\footnotetext{
57 Segundo Machado de Assis, "O que se deve exigir do escritor antes de tudo, é certo sentimento intimo, que o torne homem do seu tempo e do seu pais, ainda quando trate de assuntos remotos no tempo e no espaço."
} 
Justifica-se uma análise da obra de João Antônio devido à representação e interpretação que esta faz da experiência urbana contemporânea. Sua obra ficcional situa seus personagens em espaços urbanos metropolitanos considerados símbolos da modernização brasileira, no caso, São Paulo e Rio de Janeiro, contribuindo para a dessacralização do mito dessas metrópoles como espaços potencializadores de futuro e emancipação material e humana. Justifica-se tal análise, também, quando se considera que as obras joaoantoniana e barretiana irmanam-se na tentativa de resgatar a "voz" e a representatividade dos excluídos dos subúrbios descritos em suas narrativas. Além disso, a devoção quase canina de João Antônio em relação ao escritor carioca, como frisado por Antônio Arnoni Prado, repercutiu enormemente na sua produção literária, como fica patente ao se examinar o ensaio Calvário e Porres do Pingente Afonso Henriques de Lima Barreto.

Esta sede frenética de dar ao mundo um conhecimento mais profundo da vida dos destituídos do subúrbio é que leva o contista paulistano a fundamentar sua obra literária no homem do povo. Afinal, demonstram as estatísticas que a gente dos espaços suburbanos responde por, aproximadamente, $75 \%$ das populações urbanas do país, mas se vê privada das benesses que a urbanização reservou aos restantes cerca de $25 \%$, compostos pelos privilegiados dos "centros" e bairros nobres.

Ao entrar num corpo-a-corpo com a vida, João Antônio não sai ileso. Acredita o contista paulistano que "[...] a literatura nos ajuda a sofrer. E também, que é sofrimento que nos diverte [...]." (ANTONIO, 2004, p. 118) Nesse sentido, o autor aceita esta situação de bom grado, pois a considera inerente à condição do escritor que se dispõe a revelar a realidade brasileira. "Escrever é sangrar. Sempre, desde a Bíblia. Se não sangra é escrever?" (ANTONIO, 1987, p.324), pergunta ele. Esse sangrar a própria alma para misturá-la à tinta com que se escreve, ele aprendeu com outro mestre no mister de retratar os desvalidos e marginalizados dos subúrbios: Lima Barreto, cuja influência sobre a literatura de João Antônio é inegável.

Prova disso, é a sua recorrência constante à obra e vida do escritor carioca, por quem João Antônio possuía uma admiração e devoção quase “caninas”. Antonio Arnoni Prado confirma esta ideia fixa de João Antônio com o autor de Clara dos Anjos, ao explicar que "[...] menos pela imposição dos fatos e muito mais pela devoção pessoal que dispensa comentários, não esconde, no coração de João Antônio, uma quase obsessão pela figura de Lima Barreto [...] [grifo meu]" (PRADO, 2004, p. 241). Essa devoção de João Antônio levou-o a dedicar todas as suas obras 
ao "mestre" Lima Barreto: "A Afonso Henriques de Lima Barreto — pioneiro sempre vivo, consagro com humildade".

Literariamente, João Antônio e Lima Barreto denunciavam a hipocrisia do culto aos títulos e honrarias por parte das elites dominantes de suas épocas. Simultaneamente, investiam contra aqueles literatos que, ao invés de denunciar a opressão dessa elite sobre a gente dos subúrbios, confraternizavam com aquela. Sobre o desprezo do autor de Policarpo Quaresma pelos literatos, Antônio Arnoni Prado destaca o ressentimento para com os poderosos que "o jovem Lima Barreto ia identificando na falsa retórica de Rui Barbosa e dos literatos da Garnier, no positivismo de Barbosa Lima, 'cheio do espírito de casta e de fofa ciência' [...]." (PRADO, 2004, p. 242). O escritor paulistano partilhava igual desprezo pelos literatos, pois acreditava que o próprio ato de escrever devia consistir em uma espécie de "sacrifício" em favor dos deserdados da sociedade, talvez, até mesmo, dos próprios marginais (PRADO, 2004, p. 249).

Era opinião comum aos dois autores que o verdadeiro escritor precisava desenvolver uma literatura que primasse pela libertação dos oprimidos, desenvolvendo nos leitores aquele tipo de solidariedade que permitisse a melhoria da convivência entre os homens. Vale ressaltar, também, que na vida e na obra de ambos, é importantíssima a relação que mantêm com a cidade do Rio de Janeiro e, no caso de João Antônio, também com São Paulo.

Para João Antônio e Lima Barreto, o subúrbio era um espaço onde ainda se encontravam preservados determinados valores autenticamente nacionais, culturais e populares. Revelando-se mais puros e autênticos face às estrangeirices e maneirismos que se via e ouvia nos redutos da elite. Eis porque as produções literárias joãoantoniana e barretiana colocam-se incondicionalmente ao lado dos pobres, marginalizados e desprezados que habitam os espaços suburbanos das grandes cidades. A existência do forte elo que une os dois autores foi destacada por Alfredo Bosi, ao perceber a presença de uma saudade melancólica ao longo da obra de João Antônio:

É a procura sedenta de um passado que se tenta reconquistar no espaço de coordenadas ainda presentes mas vazias. João Antônio revive o perfil do boêmio amargo e clarividente que teve nas letras brasileiras o exemplo ardido de Lima Barreto. Mestiço, pobre, suburbano, noctívago, etílico, anarquista ou quase, homem da escrita e do jornal: quantas afinidades guardadas nas entranhas da 

memória! Por isso, o livro é 'Para Afonso Henriques de Lima Barreto pioneiro’ (BOSI, 2002, p. 239-240).

Rodrigo Lacerda aponta a originalidade da obra do escritor paulistano, demonstrada no "traço convincente de seus personagens típicos e na contribuição linguística de sua fala particular." (LACERDA, 2009 , p. 3). Eis aí um aspecto original que distingue a obra de João Antônio da de Lima Barreto: a primeira vai mais além, pois recria a linguagem e as formas peculiares de expressão corporal e facial dos malandros da periferia, como o gingado, o rebolado macio, os olhares, os sinais secretos com o corpo, as mãos e expressões faciais, criando um perfil geral, que permitiria a cada personagem se ver ali refletido.

Não que Lima Barreto não retratasse a linguagem e os costumes das gentes do subúrbio, mas ele o fazia - e esse fato foi usado até pelos que criticavam sua obra e estilo literário - de modo caricatural, não reconstruindo um padrão coerente de personagem, mas uma imagem burlesca e caricata dos seus "suburbanos". Isto se percebe, por exemplo, relativamente à linguagem, neste excerto de Clara dos Anjos: "Você sabe onde 'tá' teu 'fio'? [...] "Si" meteu com ladrão, é 'pivete' e foi 'pra chac'ra'. Eis aí que você fez, seu 'marvado', 'home mardiçoado'. [...] 'Marvado'!, Desgraçado! Caradura! Hás de 'mi pagá', 'seu canaia'!” (BARRETO, 2007, p. 116). Essa diferença entre os estilos linguísticos empregados pelos dois autores na recriação da fala dos "excluídos", se destaca ao se comparar os fragmentos acima, de Lima Barreto, com os apresentados a seguir, de João Antônio:

- Olá, meu parceirinho! Está a jogo ou a passeio? [...] Os dedos de Bacanaço indo, vindo, atiçando. Desafiavam. [...] Bacanaço meteu as mãos no bolso, estirou o beiço. Sacou a mão, o polegar dobrou-se para trás, flechou o balcão: $-O$ mister aí da casa não quer batifundo, mora. [...] Malagueta os olhava. Bacanaço boquejando, largando desafios e bazófias. Perus no acompanhamento, feito um dois de paus. 'É - pensou - quando vocês iam no moinho buscar fubá, eu, cá no meu quieto, já estava de volta com o bagulho empacotado'. E soltou para si o risinho canalha com que os malandros entendem, reconhecem. Risinho meio parado, metade na boca, metade nos olhos. Pela charla que diziam e pela manha com que vinham... ali não havia dinheiro. Então o velho se levantou, gingou nos seus 
sapatos furados e piscou o olho raiado de sangue. - A gente se junta, meus. Faz marmelo e pega os trouxas (ANTONIO, 1987, 99-108).

Flávio Aguiar ressalta, porém, que o público-leitor de João Antônio não era constituído pelos excluídos e marginalizados que representava em seus contos. Para Aguiar, o contista paulistano "não escrevia para o público que descrevia, mas sim para leitores basicamente de classe média, e de elite (a que lia tais coisas)." (AGUIAR, 2000, p.147). $\mathrm{O}$ próprio contista reconhece que o seu público leitor não é exatamente aquele que ele desejaria: "Meu leitor não é, infelizmente, o homem do povo. O livro não chega até o homem do povo. Meu leitor está nas escolas de letras e de comunicação. Meus livros são estudados nas escolas. A cultura não é um bem comum em nosso país" (ANTONIO, 1983, p. 12).

Mesmo mantendo sua independência e características literárias próprias, João Antônio se reaproxima de Lima Barreto ao elaborar o ensaio intitulado Calvário e Porres do Pingente Afonso Henriques de Lima Barreto. Neste ensaio, o escritor paulistano não apenas aproveita para revisitar a vida e obra daquele a quem considera como seu mestre, mas, simultaneamente, une-se a Lima Barreto na denúncia do processo de exclusão que a sociedade brasileira, desde o surgimento da belle époque carioca até os dias atuais, vem promovendo contra os subúrbios e seus habitantes.

O termo "pingente" presente no título do ensaio de João Antônio possui uma dupla interpretação. $\mathrm{O}$ vocábulo costuma designar aquele passageiro dos trens metropolitanos que viaja dependurado do lado de fora dos vagões, arriscando-se a cair e ser morto ou mutilado pelas rodas da composição férrea. ${ }^{58}$ Lima Barreto e João Antônio aplicam-no aos desvalidos dos subúrbios que se deslocam até o centro da cidade para trabalhar ou desenvolver atividades alternativas que lhes garantam o mínimo necessário para sobreviverem:

[...] a caracterização dos passageiros que viajam nos trens da Central do Brasil do subúrbio para o centro da cidade vai, aos poucos, sendo transformada em imensa e comovida

\footnotetext{
${ }^{58}$ Pingente: 1. Pequeno objeto pendente, em geral com a forma de pingo (...) 2. Brinco pendente. Penduricalho. 3. Bras. Passageiro que viaja no estribo de um bonde ou pendurado em qualquer veículo. HOLANDA, Aurélio Buarque de. Dicionário Aurélio Básico da Língua Portuguesa. São Paulo: Nova Fronteira, 1995, p. 506.
} 
Lima Barreto: um pingente entre a literatura e a realidade | 161 metáfora para falar de toda uma enorme população de marginalizados pelo estúpido desenvolvimento de um progresso desnorteado [...] Sendo assim, através de uma sábia combinação de dados fatuais e inserções de técnica ficcional, João Antônio consegue transformar aquilo que era apenas nomeação para os despossuídos passageiros da Zone [sic] Norte em ampla metáfora para tudo o que significa existência marginalizada por entre as contradições de uma sociedade sem resquício de racionalidade, muito menos de conforto urbano (BARBOSA, 1996, p. 14-15).

João Antônio aplica a expressão "pingente" a Lima Barreto para assinalar que não só a obra, mas a própria vida do romancista também era "pingente". O romancista carioca, assim como o contista paulistano, não apenas retratou a miséria dos subúrbios, mas vivenciou-a, sujeito às mesmas privações e problemas de outros moradores dos subúrbios. $\mathrm{O}$ escritor carioca passou a considerar que entre "lesados e os evitados pelo establishment" estavam as pessoas mais importantes do país, mexendo-se no "mutirão de pingentes urbanos, sobreviventes escorraçados lá no 'refúgio dos infelizes', o subúrbio". Elas pareciam não se enquadrar em "canto nenhum do Rio de Janeiro", mas integravam a população do Rio de Janeiro (ANTONIO, 1996, p. 86).

João Antônio notava, em 1976, com perspicácia, que tudo o que se encontrava exposto na obra de Lima Barreto, mesmo após cinquenta e quatro anos de sua morte, apresentava uma atualidade sem contestação.

Expor o "calvário" deste escritor que, pelo próprio nascimento, mulato, pobre e sem apoio da elite intelectual, se viu relegado como homem, cidadão e escritor, era uma forma de João Antônio homenageálo, aproveitando para denunciar a atmosfera de preconceito e intolerância que permeava a belle époque carioca, além de revelar que a sociedade brasileira, passados tantos anos da morte de Lima Barreto, não apresentava mudanças substanciais em sua forma de encarar e tratar os menos privilegiados. Exemplo dessa realidade encontra-se no episódio de Recordações do Escrivão Isaías Caminha, no qual o personagem principal tenta explicar o porquê de não conseguir ser bem sucedido na vida.

Não é meu propósito também fazer uma obra de ódio; de revolta enfim; mas uma defesa a acusações deduzidas superficialmente de aparências cuja essência explicadora, as mais das vezes, está na sociedade e não no indivíduo 
desprovido de tudo, de família, de afetos, de simpatia, de fortuna, isolado contra inimigos que o rodeiam, armados da velocidade da bala e da insídia do veneno [grifo meu]. (ANTONIO, 1977, p. 39).

Ao estruturar o seu ensaio, João Antônio apresenta uma espécie de roteiro da boêmia e dos bares frequentados pelo autor carioca, numa espécie de "biografia" e transcrição temática. João Antônio, durante a sua narrativa, procura entrelaçar vida e obra de Lima Barreto através de trechos de depoimentos e de alguns fragmentos de seus romances, e a reprodução de documentos e frases de outros escritores sobre o autor de Isaias Caminha. Ou seja, de certa forma, Lima Barreto entra para o ensaio de João Antônio como um personagem ficcional. Assim, é possível verificar uma aparente identificação entre o escritor, Lima, e suas personagens. Além da boêmia e das andanças pelos diversos bares do centro do Rio, Lima Barreto estava sempre em companhia de seus amigos, os quais, em sua grande maioria, eram pobres, maltrapilhos, desempregados que vinham dos bairros mais distantes para, ali, se encontrarem com o personagem romancista..$^{59}$

As peregrinações de Lima Barreto pelos bares e botequins do centro do Rio começaram por volta de 1916. Calvário e Porres informa que a primeira parada do dia para Lima acontecia em um pequeno bar da rua Sachet, onde este cultivava uma roda de amigos com quem bebia e conversava, em geral, das três às cinco horas. Em seguida, se dirigia para a Avenida Rio Branco, para entregar sua colaboração jornalística diária na sede da revista Careta. A roda frequentada por Lima Barreto morava, em sua maioria, em bairros acessiveis por bondes elétricos. Lima, ao contrário, apanhava o trem na Estação Central, descia em Todos os Santos, e de lá tocava até Inhaúma, o que demonstra que ele era o único "suburbano" do grupo.

Ao deixar a sede da revista, ele dirigia-se à Rua do Rosário, passava pela esquina da Rua do Ouvidor, seguindo pela Miguel Couto e Rua do Rosário, indo até o Largo de São Francisco. No Beco do Rosário, Lima fazia uma parada mais prolongada, para encontrar com alguns

\footnotetext{
${ }^{59}$ Para efeito de melhor padronização desta seção terciária, fica subentendido que todas as referências seguintes sobre Lima Barreto, a menos que seja indicado em contrário, estarão se referindo ao "personagem" Lima Barreto, protagonista da obra Calvário e Porres do Pingente Lima Barreto, de João Antônio. Se considerarmos necessário algum esclarecimento sobre determinado episódio da vida real de Lima Barreto nos referiremos ao mesmo como o escritor Lima Barreto.
} 
companheiros habituais desse roteiro. Nesse Beco, havia pequenos bares propícios para reuniões de amigos.

Ao contrário da roda frequentada na Rua Sachet, os amigos do Beco do Rosário eram pessoas modestas, como, por exemplo, funcionários públicos que não haviam ascendido nas respectivas carreiras, mais por falta de instrução do que propriamente por falta de inteligência. Gente tipicamente suburbana como Lima Barreto. Sua predileção pelo convívio com os moradores dos subúrbios cariocas é uma das principais razões para a admiração confessa por estes seres humanos, que lutavam com galhardia pela própria sobrevivência. Um fragmento de Recordações do Escrivão Isaias Caminha denota, pela "voz" de um personagem, a admiração do escritor pelos habitantes das esferas desprezadas da sociedade.

Admirava-me que essa gente pudesse viver, lutando contra a fome, contra a moléstia e contra a civilização, que tivesse energia para viver cercada de tantos males, de tantas privações e dificuldades. Não sei que estranha tenacidade a leva a viver e por essa tenacidade é tanto mais forte quanto mais humilde e miserável [grifo meu] (ANTONIO, 1977, p. 36).

Lima Barreto, em suas andanças pelas ruas cariocas parava, ainda, em mais dois bares: um na Rua da Conceição, na esquina da José Maurício com Buenos Aires. O outro, ficava na lateral da Estação Dom Pedro II, onde o escritor se demorava bem mais, pois ali era ponto de encontros no Rio de Janeiro de 1916. Nesse bar, além de humildes burocratas, ele confraternizava com antigos amigos da Central do Brasil e do Ministério da Guerra. Em seguida, tomava o bonde para Todos os Santos, e dali para Inhaúma.

Em virtude dessas andanças pelos bares e cafés do centro do Rio, Lima Barreto travava contato com exemplares das diversas classes sociais da metrópole. Esse contato permitia-lhe traçar um retrato literário das interações e conflitos entre representantes das camadas privilegiadas e excluídas, que ele repassava para seus romances, na pele de seus personagens. Em um prefácio de Eloy Pontes para uma das edições de Recordações do Escrivão Isaías Caminha, há um conselho para quem deseja aprender a escrever livros: "Quando você principiar a escrever, tome um trem aqui, viaje até a Central, de segunda classe, e terá assunto, não para 
um pequeno conto apenas, mas para um livro de muitas páginas" (ANTONIO, 1977, p. 23).

Ao viajar de trem junto aos integrantes das camadas excluídas da sociedade, o futuro escritor terá acesso, entre outras coisas, a uma série de estímulos, como cheiros, sons, cores e matizes variados, típicos das populações pobres. Além disso, os conflitos e situações tragicômicas que ocorrem nesses vagões férreos também poderão ser presenciados e mesmo experimentados pelo investigador, que contará com boa quantidade de material informativo para o desenrolar de suas narrativas.

Em Calvário e Porres, verificamos que após sua incursão pela obra e vida de Lima Barreto e, inclusive, tornando este, um de seus personagens, João Antônio pouco menciona, pelo menos de forma direta, sobre a morte do grande escritor do primeiro quarto do século XX. Talvez, um dos motivos para que João Antônio deixasse de mencionar a morte física de Lima tenha sido o desejo de, por meio deste artifício, preservar a vida literária do escritor carioca, tentando reavivar o interesse das pessoas pela obra barretiana, garantindo, assim, que ele, de certa forma, continuasse vivo no campo da literatura brasileira. Seja como for, o que é certo é que não há como negar a forte influência de Lima Barreto na produção joãoantoniana, nem a identificação entre os objetivos de ambos os autores: o resgate da vida, das venturas e desventuras das gentes dos bairros periféricos e a denúncia do cruel processo de exclusão a que se veem submetidos pela urbanização das metrópoles.

O escritor Lima Barreto, deixou, atrás de si, uma fecunda e instigante produção literária que, para João Antônio, permite ver "[...] um povo com suas caras, lutas, dores, dramas, sonhos, costumes, vida, enfim. Lima foi o responsável pela entrada do povo urbano, enquanto massa, volume e alma, no território da literatura brasileira" (SILVA, 2005, p. 277). Calvário e Porres, nada mais foi, afinal, do que a última e maior dedicatória de João Antônio ao "pingente" Afonso Henriques de Lima Barreto. Para sempre, um pioneiro. Para sempre vivo.

\section{REFERENNCIAS}

AGUIAR, Flávio. Evocação de João Antônio ou do purgatório ao inferno. In: CHIAPPINI, Ligia; DIMAS, Antonio; ZILLY, Berthold (orgs.) Brasil, pais do passado? São Paulo: EDUSP/Boitempo, 2000. 
Lima Barreto: um pingente entre a literatura e a realidade | 165 ANTÔNIO, João (org.). Calvário e porres do pingente Afonso Henriques de Lima Barreto. Rio de Janeiro: Civilização Brasileira, 1977.

ANTÔNIO, João. O buraco é mais embaixo. In: Realidade Brasileira. Malditos Escritores. São Paulo: Edições Símbolo, mar. 1977 [Material fornecido pela UNESP].

- Malagueta, Perus e Bacanaço $\mathcal{E}$ malhação do Judas carioca. São Paulo: Clube do Livro, 1987.

. Conheci a aguardente de pêssego e os palavrões húngaros, a música cigana, o som do violino. O Estado de São Paulo. 13 dez. 1983, p 12, n. 140.

ANTÔNIO, João. Dama do Encantado. São Paulo: Nova Alexandria, 1996.

. Cartas aos amigos Caio Porfírio Carneiro e Fábio Lucas. Cotia, SP: Ateliê Editorial, 2004.

ASSIS, Machado de. Obras completas de Machado de Assis. Rio de Janeiro: W. M. Jackson Inc. Editores, 1955.

BARBOSA, João Alexandre. A prosa de uma consciência. In: ANTÔNIO, João. Dama do Encantado. São Paulo: Nova Alexandria, 1996. Prefácio.

BARRETO, Lima. Triste fim de Policarpo Quaresma. São Paulo: Ática, 1996. Série Bom Livro.

. Clara dos Anjos. São Paulo: Ática, 2007. Série Bom Livro.

BOSI, Alfredo. Um boêmio entre duas cidades. In: Literatura e resistência. São Paulo: Companhia das Letras, 2002.

CANDIDO, Antonio. A formação da literatura brasileira: momentos decisivos. 4 ed. São Paulo: Martins Fontes, 1975.

HOlANDA, Aurélio Buarque de. Dicionário Aurélio Básico da Lingua Portuguesa. São Paulo: Nova Fronteira, 1995. 
166 | Camila Marcelina Pasqual

LACERDA, Rodrigo. O primeiro amor de João Antônio. In: ANTÔNIO, João. Malagueta, Perus e Bacanaço $\mathcal{E}$ malhação do Judas carioca. São Paulo: Cosac \& Naify, 2009.

PRADO, Antonio Arnoni. Lima Barreto personagem de João Antônio. In: Trincheira, palco e letras. São Paulo: Cosac \& Naify, 2004.

Recebido em: 26/08/2016

Aceito em: 21/09/2016 